\title{
Slow-Channel Transgenic Mice: A Model of Postsynaptic Organellar Degeneration at the Neuromuscular Junction
}

\author{
Christopher M. Gomez, ${ }^{1,2}$ Ricardo Maselli, ${ }^{3}$ Jo Ellen Gundeck, ${ }^{1}$ Mary Chao, ${ }^{3}$ John W. Day, ${ }^{1}$ \\ Shiori Tamamizu, ${ }^{4}$ Jose A. Lasalde, ${ }^{4}$ Mark McNamee, ${ }^{4}$ and Robert L. Wollmann ${ }^{5}$ \\ ${ }^{1}$ Department of Neurology, 2Institute of Human Genetics, University of Minnesota, Minneapolis, Minnesota 55455, \\ Sections of ${ }^{3}$ Neuroscience and ${ }^{4}$ Molecular and Cellular Biology, University of California, Davis, California, and ${ }^{5}$ Section of \\ Neuropathology, University of Chicago, Chicago, Illinois 60637
}

\begin{abstract}
The slow-channel congenital myasthenic syndrome (SCCMS) is a dominantly inherited disorder of neuromuscular transmission characterized by delayed closure of the skeletal muscle acetylcholine receptor $(\mathrm{AChR})$ ion channel and degeneration of the neuromuscular junction. The identification of a series of AChR subunit mutations in the SCCMS supports the hypothesis that the altered kinetics of the endplate currents in this disease are attributable to inherited abnormalities of the AChR. To investigate the role of these mutant AChR subunits in the development of the synaptic degeneration seen in the SCCMS, we have studied the properties of the AChR mutation, $\epsilon \mathrm{L} 269 \mathrm{~F}$, found in a family with SCCMS, using both in vitro and in vivo expression systems. The mutation causes a sixfold increase in the open time of AChRs expressed in vitro, similar to the phenotype of other reported mutants. Transgenic mice expressing this mutant develop a syndrome that is highly reminiscent of the
\end{abstract}

SCCMS. Mice have fatigability of limb muscles, electrophysiological evidence of slow AChR ion channels, and defective neuromuscular transmission. Pathologically, the motor endplates show focal accumulation of calcium and striking ultrastructural changes, including enlargement and degeneration of the subsynaptic mitochondria and nuclei. These findings clearly demonstrate the role of this mutation in the spectrum of abnormalities associated with the SCCMS and point to the subsynaptic organelles as principal targets in this disease. These transgenic mice provide a useful model for the study of excitotoxic synaptic degeneration.

Key words: transgenic mice; neuromuscular junction; slowchannel congenital myasthenic syndrome; acetylcholine receptor; point mutation; calcium overload; excitotoxicity; synaptic degeneration
The slow-channel congenital myasthenic syndrome (SCCMS) is a dominantly inherited disorder of neuromuscular transmission in which electrophysiological features of abnormal acetylcholine receptor $(\mathrm{AChR})$ ion channel kinetics have been associated with point mutations in the genes encoding the subunits of the AChR (Engel et al., 1982; Oosterhuis et al., 1987; Gomez and Gammack, 1995; Sine et al., 1995; Ohno et al., 1995; Engel et al., 1996; Gomez et al., 1996b). It is the first of what may be a family of disorders of altered or exaggerated synaptic receptor function that underlie poorly understood neurodegenerative, convulsive, or psychiatric disorders (Shiang et al., 1993; Steinlein et al., 1995; Treinin and Chalfie, 1995; Ophoff et al., 1996). Several studies have correlated the changes in the kinetics of endplate currents with the in vitro phenotype of the mutant subunits. In this study we seek to associate the changes in ion channel properties with the striking clinical and pathological features of this disease.

The SCCMS is characterized clinically by fatigability and progressive weakness and atrophy of the skeletal muscles, especially

Received Jan. 14, 1997; revised March 17, 1997; accepted March 21, 1997.

This work was supported by National Institutes of Health Clinical Investigator Development Award K08NS01540 and Muscular Dystrophy Association Grant R01 NS33202.

Correspondence should be addressed to Dr. Christopher M. Gomez, Department of Neurology, P.O. Box 295, University of Minnesota, 420 Delaware Street SE, Minneapolis, MN 55455.

Dr. Lasalde's present address: University of Puerto Rico, Department of Biology, P.O. Box 23360, San Juan, PR 00931-3360.

Copyright (C) 1997 Society for Neuroscience $0270-6474 / 97 / 174170-10 \$ 05.00 / 0$ of the extraocular, face, and forelimb (Engel et al., 1982; Oosterhuis, et al., 1987). The distinctive pathological features are found at the electron microscopic level (Engel et al., 1982; Oosterhuis et al., 1987; Gomez et al., 1996b) and consist of striking degenerative changes involving the basement membrane, postsynaptic membrane, and subsynaptic organelles of the neuromuscular junction. One possible explanation for these changes is that the slowed channels, normally permeable to sodium and calcium ions (Decker and Dani, 1990), allow entry of excessive amounts of these cations, which activate any of several degradative (Engel et al., 1982; Salpeter et al., 1982) or second-messenger pathways (Bygrave and Roberts, 1995; Ghosh and Greenberg, 1995). Confirmation of this hypothesis and elucidation of the factors and processes responsible for the synaptic degeneration in SCCMS may aid in understanding the basis for the excitotoxic neuronal damage in conditions such as stroke, epilepsy, and neurodegenerative diseases. Moreover, identification of the functional differences among distinct AChR mutations that account for observed differences in clinical, pathological, and electrophysiological features of the SCCMS will greatly expand our understanding of excitotoxicity and of excitatory synaptic transmission.

Recently we reported the occurrence of a mutation, $\epsilon \mathrm{L} 269 \mathrm{~F}$ (Gomez and Gammack, 1995), in the sequence encoding the channel-lining domain of the $\epsilon$ subunit in the three affected members of a kindred with SCCMS. To investigate the role of this mutant subunit in the pathogenesis of the constellation of electrophysiological and pathological features constituting the SCCMS, we studied its properties in vitro and in vivo. Our findings 
demonstrate that this mutation is responsible for the kinetic abnormality of the AChR observed in these patients and for the development of $\mathrm{Ca}^{2+}$ overload and endplate degeneration in the SCCMS.

\section{MATERIALS AND METHODS}

In vitro expression studies. Site-directed mutagenesis of mouse $\epsilon$ subunit cDNA to generate the homologous L269F mutation was performed using single-stranded plasmid generated from the vector pSelect (Promega, Madison, WI). The mutation was confirmed by dideoxy nucleotide sequence determination. Mutant and wild-type AChR subunit mRNAs (Lapolla et al., 1984; Boulter et al., 1985; Gardner, 1990) were transcribed in vitro from linearized plasmids using $\mathrm{T} 7$ polymerase. Plasmids containing the cDNAs for the $\alpha, \beta, \delta$, and $\epsilon$ subunits of mouse AChR were linearized by restriction enzyme digestion and were used as templates for T7 RNA polymerasemediated in vitro transcription. Transcription was performed in the presence of the cap analog m7G95')ppp (5')G,5'-7-methyl guanosine. Purification of RNA transcripts was performed using Select-D(RF) columns (5 Prime-3 Prime, Boulder, CO). Ovarian lobes were obtained from female Xenopus laevis. Follicle cell layers were removed by incubation of the oocytes in $\mathrm{Ca}^{2+}$-free OR2 buffer containing $82.5 \mathrm{~mm} \mathrm{NaCl}, 2.5 \mathrm{~mm} \mathrm{KCl}, 1 \mathrm{~mm} \mathrm{MgCl}$, $1 \mathrm{mM} \mathrm{Na}_{2} \mathrm{HPO}_{4}$, and $5 \mathrm{~mm} \mathrm{HEPES}$, pH 7.6, plus $2 \mathrm{mg} / \mathrm{ml}$ collagenase (Type 1A, Sigma, St. Louis, MO) for $20 \mathrm{~min}$ at room temperature under slow agitation (80-100 rpm) followed by manual defolliculation. Oocytes of stage $\mathrm{V}$ and VI were chosen for injection. Fifty nanoliters of mRNA subunit transcripts of mouse AChR (at a concentration of $0.4 \mathrm{ng} / \mathrm{nl}$ ) were injected into the cytoplasm of Xenopus oocytes at an $\alpha: \beta: \delta: \epsilon$ ratio of 2:1:1:1.

Generation and screening of transgenic lines. The design for the transgene construct, $\mathrm{MCK} \epsilon \mathrm{L} 269 \mathrm{~F}$, was analogous to previous transgenes (Gomez et al., 1996a). In brief, the cDNA encoding the mutant $\epsilon$ subunit, $\epsilon \mathrm{L} 269 \mathrm{~F}$, was joined to the $3^{\prime}$ end of a $3.3 \mathrm{~kb}$ portion of the mouse creatine kinase promoter (Johnson et al., 1989). The $3^{\prime}$ untranslated end of the $\epsilon \mathrm{L} 269 \mathrm{~F}$ cDNA was removed and replaced with the $3^{\prime}$ untranslated region of the bacterial neomycin resistance gene (NEO) and the SV40 small-t intron to allow distinction of transgene mRNA. The nucleotide sequence of the junction points and $\epsilon \mathrm{L} 269 \mathrm{~F}$ cDNA were confirmed by dideoxy sequence analysis.

Transgenic mice bearing $\mathrm{MCK} \epsilon \mathrm{L} 269 \mathrm{~F}$ were generated by microinjection of single-cell mouse embryos of the strain FVB, as described by Hogan et al., (1986). The genetic background was assumed not to be critical for these experiments. Genomic DNA extracted from mouse tail tips by standard methods (Sambrook et al., 1989) was screened for the presence of the transgene by the PCR (Saiki et al., 1988), using primers corresponding to sequences the $\epsilon$ subunit (Gardner, 1990) and the NEO gene (Gorman et al., 1982).

Analysis of transgene expression. Ten micrograms total RNA extracted from hindlimb skeletal muscle (Chomczynski and Sacchi, 1987) of F1 mice of each of the four propagated lines and control mouse was sizeselected by agarose gel electrophoresis in $6 \%$ formaldehyde, transferred to nylon membranes, and stabilized by UV cross-linking. DNA probes for hybridization (Feinberg and Vogelstein, 1984; Sambrook et al., 1989) consisted of a $450 \mathrm{bp}$ Pst 1 fragment from the $3^{\prime}$ portion of the transgene, containing both $\epsilon$ AChR and transgene-specific NEO sequences and the $300 \mathrm{bp} \mathrm{3'}$ untranslated region of the mouse MCK gene (MCK 3') (Buskin et al., 1985), as a probe for comparable loading of lanes.

Immunolocalization of AChR subunits. Transverse sections of fresh frozen mouse forelimb muscle $(8-20 \mu \mathrm{m})$ were collected on silanized glass slides and allowed to air dry. Sections were incubated 3-5 min in 50 $\mathrm{mm}$ ethanolamine hydrochloride, $\mathrm{pH} 11$, to remove cytoskeletal proteins, rinsed three times for 10 min each in PBS, $\mathrm{pH} 7.2$ then immersed in PBS containing $4 \%$ normal donkey serum (D-PBS) $\times 30 \mathrm{~min}$. Sections were next immersed in D-PBS containing either a 1:200 dilution of affinitypurified rabbit anti- $\gamma$-subunit peptide (anti- $\gamma 485$, gift of $Z$. Hall, National Institute of Neurological Disorders and Stroke) (Gu and Hall, 1988) or 50 $\mu \mathrm{g} / \mathrm{ml}$ of one of four subunit-specific monoclonal antibodies (mAbs), 132A (rat anti- $\alpha$ subunit) (Gomez and Richman, 1985), 111 (rat anti- $\beta$ subunit, gift of J. Lindstrom, University of Pennsylvania) (Tzartos and Lindstrom, 1980), 88B (mouse anti- $\gamma-\delta$ subunit, gift of S. Froehner, University of North Carolina, Chapel Hill) (Froehner et al., 1983) or 168 (rat anti- $\epsilon$ subunit, gift of J. Lindstrom) (Nelson et al., 1992) for $1 \mathrm{hr}$. To remove unbound antibody, sections were then rinsed in PBS as described above. Sections were then immersed in D-PBS containing either Cy2conjugated $\alpha$-bungarotoxin (Cy2-BT, $5 \mu \mathrm{g} / \mathrm{ml}$; Molecular Probes, Eugene, OR) together with Cy3-conjugated goat anti-mouse (or-rat) $\mathrm{IgG}$
(1:200 dilution) or Texas red-conjugated $\alpha$-bungarotoxin (Tx-BT, $5 \mu \mathrm{g} /$ $\mathrm{ml}$; Molecular Probes) together with Cy2-conjugated donkey anti-rabbit IgG (1:200 dilution). Denervated muscle was used as a positive control for the anti- $\gamma$ subunit peptide antisera. Stained, washed sections were viewed, and images were digitized using a Bio-Rad MRL 1024 confocal head Richmond, CA and Olympus BX 60 microscope. Images from each label were merged using a graphics program (Photoshop).

Clinical evaluation of muscle strength. Two apparatuses were used to assess forelimb muscle strength. The first consisted of a 6-mm-diameter wooden dowel suspended fixed over a height of $35 \mathrm{~cm}$. Mice were placed on top of the dowel and observed for periods of up to $60 \mathrm{sec}$. The possible outcomes consisted of escape or persistence on the dowel for the entire period (score of $100 \%$ ) or falling off before $1 \mathrm{~min}$ is reached (scored as the fraction of $1 \mathrm{~min}$ ). This test evaluates more complex motor skills as well as strength and endurance. The second test consisted of a taut wire suspended in place of the dowel. For testing, mice were placed with front claws gripping the wire and observed for periods of up to $60 \mathrm{sec}$. Possible outcomes and scoring were identical. This test more strictly evaluated strength and endurance alone. For each test, five sets of three repetitions were conducted. The mean and SE for 15 tests were calculated using a statistical program (Excel, Microsoft). Mice were tested blindly using littermate controls.

Electromyography. Compound muscle action potentials (CMAPs) were studied as described by Gomez et al., (1996a). For hindlimb recordings, animals were anesthetized with pentobarbital or Avertin (Hogan et al., 1986), and the sciatic nerves were exposed. The responses from both the gastrocnemius and intrinsic hindpaw muscles were recorded separately during direct sciatic nerve stimulation. For the intrinsic hindpaw, muscle recording electrodes were placed at the wrist and at the base of the third digit. Wounds were closed with stainless steel wound clips. For forelimb recordings, the stimulus electrode was placed into the brachial plexus, and a stable EMG response was sought. Responses were recorded and displayed using a clinical electromyography apparatus (Dantec Counterpoint). The fractional decrease in amplitude of the CMAP (decrement) was calculated using the amplitude (peak positive to peak negative) of the 1 st and 10th responses. The mean and SE of the decrement at $5 \mathrm{~Hz}$ stimulation for six transgenic and five control mice were calculated using a statistical program (Excel, Microsoft).

Voltage-clamp. Recordings of miniature endplate currents (MEPCs) from the diaphragm were performed using electrophysiologic techniques described previously (Maselli et al., 1989, 1991). All the microelectrode recordings were performed in the most posterior aspect of the left hemidiaphragm muscle. This part of the muscle is very thin (one or two layers of muscle fibers), allowing excellent endplate visualization (Dow Corning, Arlington, TN). After dissection the muscles were pinned to SYLGARD (Dow Corning, Arlington, TN) on the bottom of a Plexiglas chamber. The chamber was subsequently placed on the stage of an upright microscope (Leitz Laborlux 12) equipped with Hoffman interference contrast optics (magnification, 250 $\times$ ). The preparations were bathed continuously in Tyrode's solution having the following ionic composition (in $\mathrm{mM}$ ): $\mathrm{NaCl} 140, \mathrm{KCl} 2.6, \mathrm{MgCl}_{2} 0.4, \mathrm{CaCl}_{2} 2.5$, and $\mathrm{NaH}_{2} \mathrm{PO}_{4}, \mathrm{pH}$ 7.4. The solution was bubbled with a $95 \% \mathrm{O}_{2}, 5 \% \mathrm{CO}_{2}$ gas mixture, and the $\mathrm{pH}$ was maintained between 7.3 and 7.4. Experiments were performed at room temperature $\left(26^{\circ} \mathrm{C}\right)$ using an Axoclamp $2 \mathrm{~A}$ (Axon Instruments, Foster City, CA). The two electrode regional voltagecurrent electrodes were filled with $3 \mathrm{M} \mathrm{KCl}$ and had resistances in the range of 8-12 M $\Omega$ for the voltage electrode and 2-4 $\mathrm{M} \Omega$ for the current electrode. Extensive ground shielding between the two electrodes was necessary to minimize coupling capacitance. The output of the recording instrument was amplified, filtered, and sampled at $10 \mathrm{Khz}$ by a 12 bit analog to digital converter (Data Translation 2818, Marlboro, MA). All electrical signals were acquired on-line and stored on a personal computer for subsequent analysis. Exponential fits to the MEPC decays were performed using a nonlinear least square fitting routine.

Single-channel studies using the patch-clamp technique. For oocyte experiments, the oocyte vitelline membrane was removed manually after incubation in hypertonic solution composed of $150 \mathrm{~mm} \mathrm{NaCl}, 2 \mathrm{mM} \mathrm{KCl}$, $3 \%$ sucrose, and $5 \mathrm{~mm}$ HEPES, $\mathrm{pH}$ 7.6. The oocytes were placed in a recording chamber containing bath solution $\left(100 \mathrm{mM} \mathrm{KCl}, 1 \mathrm{mM} \mathrm{MgCl}_{2}\right.$, and $10 \mathrm{~mm}$ HEPES, $\mathrm{pH} 7.2$ ) at $18^{\circ} \mathrm{C}$. The patch pipettes were made of thick-walled borosilicate glass (Sutter Instruments, Novato, CA) exhibiting resistances of 8-12 M . The pipette solution contained $100 \mathrm{~mm} \mathrm{KCl,}$ $10 \mathrm{~mm}$ HEPES, $10 \mathrm{~mm}$ EGTA, pH 7.2, and $4 \mu \mathrm{M}$ ACh. All experiments were performed in a cell-attached configuration. Single-channel currents were recorded using a Dagan 3900 amplifier (Dagan, Minneapolis, MN), 
filtered at $5 \mathrm{kHz}$ (Frequency Devices, Haverhill, MA) and stored on VHS tapes using a digital data recorder (VR-10B, Instrutech, Mineola, NY). The data traces were played back into an IBM-compatible computer through DigiData 1200 interface (Axon Instruments) and digitized at 50 $\mu$ sec. Single-channel currents were detected with a half-amplitude crossing algorithm (IPROC 3), and data analysis was performed using pCL/ AMP 6 (Axon Instruments).

Standard cell-attached patch-clamp techniques (Brehm and Kullberg, 1987) were used to record ACh-gated single channels. The flexor digitorum brevis (fdb) muscles from mice were dissociated acutely. The muscles were treated with $0.2 \%$ collagenase (type $1 \mathrm{~A}$, Sigma), followed by gentle trituration. Patch-clamp recordings were performed on single fibers bathed in a physiological saline solution $(120 \mathrm{~mm} \mathrm{NaCl}, 1 \mathrm{~mm} \mathrm{KCl}, 1 \mathrm{~mm}$ $\mathrm{CaCl}_{2}, 10 \mathrm{~mm}$ HEPES buffer, $\mathrm{pH}$ 7.2) at room temperature. The patchclamp electrodes were fabricated from borosilicate glass using a two-stage Narishige puller (Narishige 9-28 Kasuya 4-chrome, Setagaya-ku, Tokyo, Japan) to obtain a diameter of $1 \mu \mathrm{m}$. The electrodes were coated with SYLGARD to reduce capacitance and recording noise. Finally, the electrodes were fire-polished with Narishige forge and backfilled with 200-400 nM ACh diluted in HEPES buffer. Single-channel currents were recorded and amplified with an Axopatch 200 amplifier (Axon Instruments). Single currents were filtered with a low-pass Bessel filter ( 80 $\mathrm{dB} /$ decade) set at $2 \mathrm{kKz}$ and input to a TL-1 interface for digital conversion. The currents were recorded on-line using a personal computer loaded with pClamp software (Axon Instruments). All data analysis, including open-time and close-time histogram were done using pClamp 6 software.

Pathology. Fresh frozen sections of forelimb flexors and extensor muscles, biceps, triceps, tibialis anterior, gastrocnemius, soleus, and diaphragm were examined for light microscopic studies. The Karnovsky and Roots cholinesterase method was used to localize endplates (Namba et al., 1967) and the glyoxal bis-(2-hydroxyanil) (GBHA; Kashiwa, 1970) or von Kossa (Rungby et al., 1993) methods were used to localize $\mathrm{Ca}^{2+}$. Acid phosphatase was localized using an azo-dye method (Barka, 1960).

For electron microscopy mice were perfused with $2 \%$ glutaraldehyde by cardiac puncture. Forelimb flexor muscles were then removed and fixed overnight in fresh glutaraldehyde, rinsed in $0.1 \mathrm{M}$ phosphate buffer. The muscle bellies were teased into $1 \mathrm{~mm}$ bundles, osmicated, and embedded in Epon.

\section{RESULTS}

\section{Effect of the $\epsilon$ L269F mutation on AChRs expressed in Xenopus oocytes}

The $\epsilon$ L269F mutation is present in the three affected members of a family with the SCCMS (Gomez and Gammack, 1995). To confirm that this mutation was not a silent polymorphism in the $\epsilon$ AChR subunit gene, we generated the identical mutation in the mouse $\epsilon$ subunit in Xenopus oocytes. Oocytes injected with mouse wild-type $\alpha, \beta, \delta$, and $\epsilon$ subunit cRNAs exhibit channel openings typical of the adult AChR (Mishina et al., 1986). As shown in Figure 1 and Table 1, the open-time distribution of wild-type AChR (top) shows two components, $\tau_{0}, 0.75 \mathrm{msec}(f=0.158)$, and $\tau_{1}, 3.63 \mathrm{msec}(f=0.842)$, where $f$ refers to the fraction of the total events with the indicated open time. The $\epsilon \mathrm{L} 269 \mathrm{~F}$ mutation increases the AChR single-channel, open-time significantly. The open-time distribution of $\epsilon \mathrm{L} 269 \mathrm{~F}$ (bottom panels) shows three components at $-100 \mathrm{mV}$ and $18^{\circ} \mathrm{C}: \tau_{0}, 4.21 \mathrm{msec}(f=0.161)$; msec $\tau_{1}, 19.95 \mathrm{msec}(f=0.452)$, and $\tau_{2}, 45.44 \mathrm{msec}(f=0.387)$, indicating a pronounced slowing of channel closure.

\section{Generation and characterization of transgenic lines}

Of five founder mice bearing the transgene MCK $\epsilon$ L269F, four $(\epsilon 5, \epsilon 9, \epsilon 12$, and $\epsilon 14)$ were successfully propagated by breeding. The founder $\epsilon 4$ did not breed, although electrophysiological and histological studies indicated that it was severely affected. Southern blot analysis of genomic digests indicated that in each line the transgene was integrated head to tail at a single site, with line $\epsilon 9$ having 2 copies, lines $\epsilon 5$ and $\epsilon 14$ having 5 copies, and line $\epsilon 12$ having 25 copies (data not shown).
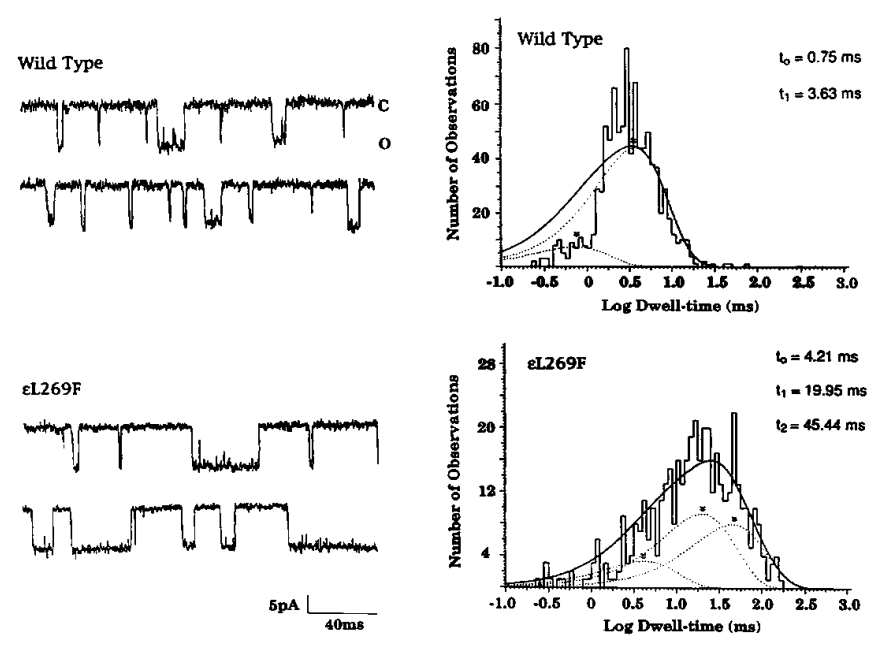

Figure 1. The $\epsilon \mathrm{L} 269 \mathrm{~F}$ mutation causes increased $\mathrm{AChR}$ channel open times. Single-channel currents (left) and open time histogram (right) for wild-type mouse AChRs (top) and AChRs expressing the $\epsilon$ L269F mutation (bottom) expressed in Xenopus oocytes. Recordings were performed at $-100 \mathrm{mV}$ and $4.0 \mu \mathrm{M}$ ACh. The $\epsilon \mathrm{L} 269 \mathrm{~F}$ mutation shows three open time components: $\tau_{0}, 4.21 \mathrm{msec}(f=0.161) ; \tau_{1}, 19.95 \mathrm{msec}(f=0.452)$, and $\tau_{2}, 45.44 \mathrm{msec}(f=0.387)$, total detected events $(2,061)$. The wild type only show two main components: $\tau_{0}, 0.75 \mathrm{msec}(f=0.158)$ and $\tau_{1}$, $3.63 \mathrm{msec}(f=0.842)$, total detected events $(1995)$. The analysis was performed using the Marquardt least squares fitting in pClamp6.

\section{Expression studies in vivo}

Figure 2 shows the results of an RNA blot analysis of skeletal muscle RNA from control and four lines of $\epsilon$ L269F-transgenic mice. Mice from all four lines studied have detectable steady state levels of the $2.6 \mathrm{~kb}$ transgene mRNA. The level of expression ranges approximately eightfold with line $\epsilon 9$ having the lowest level of expression, lines $\epsilon 5$ and $\epsilon 12$ approximately threefold over that of line $\epsilon 9$, and line $\epsilon 14$ approximately eightfold over that of line $\epsilon$. Because, at this level of sensitivity the mRNA from the wild-type $\epsilon$ subunit is undetectable (Merlie and Sanes, 1985), the transgene mRNA level exceeds the abundance of endogenous $\epsilon$ subunit. The two smaller RNA species could result either from aberrant splicing or from differential polyadenylation.

Marked overexpression of the $\epsilon \mathrm{L} 269 \mathrm{~F}$ transgene could theoretically alter the subunit composition of endplate AChRs. We used AChR subunit-specific antibodies to test for the presence of the normal AChR subunits. Figure $3 A$ demonstrates the binding of the $\gamma$ - $\delta$-specific monoclonal antibody, $88 \mathrm{~B}$, to transgenic mouse endplates. The yellow-stained endplates demonstrate that there is colocalization of the green-staining Cy2-BT with the red-staining Cy-3-labeled $\gamma-\delta$ epitope. Figure $3 B$ demonstrates the absence of binding of the anti- $\gamma$ antibody to the endplates on a serial section, which stain only with Tx-BT. This confirms that $\mathrm{mAb} 88 \mathrm{~B}$ readily detects the $\delta$-subunit in the $\epsilon$ L269F-endplates. As a positive control for the peptide-specific antiserum, Figure $3 B$, inset, shows the binding of the anti- $\gamma$ antisera to endplates in neonatal muscle in the same experiment. Similar endplate staining was seen with mAbs specific for $\alpha, \beta$, and $\epsilon$ subunits. Therefore, the overexpression of the mouse $\epsilon$ subunit mutant $\epsilon$ L269F does not prevent the formation of AChRs with the normal AChR subunit composition.

\section{Clinical studies}

By 6-8 weeks of age all transgenic mice from lines $\epsilon 5, \epsilon 12$, and $\epsilon 14$, the three high-expressing lines, are distinguished from their littermate controls by the presence of a faster respiratory rate. By 


\begin{tabular}{|c|c|c|c|c|c|c|}
\hline \multirow[b]{2}{*}{ Feature } & \multicolumn{2}{|c|}{ Mouse muscle ${ }^{a}$} & \multicolumn{2}{|l|}{ Oocyte $^{b}$} & \multicolumn{2}{|c|}{ Human muscle ${ }^{c}$} \\
\hline & $\epsilon \mathrm{L} 269 \mathrm{~F}$ & Control & $\epsilon \mathrm{L} 269 \mathrm{~F}$ & Control & $\epsilon \mathrm{L} 269 \mathrm{~F}$ & Control \\
\hline \multicolumn{7}{|l|}{ Channel open times } \\
\hline$\tau_{0}$ & 0.52 & 0.31 & 4.21 & 0.75 & 0.19 & 0.12 \\
\hline$\tau_{1}$ & 13.2 & 3.85 & 19.95 & 3.63 & 2.92 & 3.04 \\
\hline$\tau_{2}$ & $\mathrm{ND}^{\mathrm{d}}$ & ND & 45.44 & ND & 16.67 & ND \\
\hline Channel conductance ${ }^{\mathrm{e}}$ & 76.5 & 75.1 & & & & \\
\hline Muscle action potentials per nerve stimulus ${ }^{f}$ & $2-3$ & 1 & & & & \\
\hline Decremental response ${ }^{g}$ & 13.6 & 3.0 & & & & \\
\hline MEPC amplitude ${ }^{\mathrm{h}}$ & 2.0 & 2.9 & & & & \\
\hline \multicolumn{7}{|l|}{ MEPC decay phases ${ }^{\mathrm{i}}$} \\
\hline$\tau_{\mathrm{s}}$ & 7.89 & 1.44 & & & & \\
\hline$\tau_{1}$ & 0.81 & 0.12 & & & & \\
\hline$\tau_{2}$ & 26.6 & 3.47 & & & & \\
\hline
\end{tabular}

SE and $p$ values included in Results.

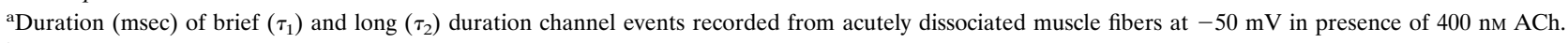

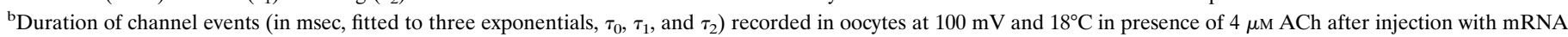
corresponding to $\epsilon \mathrm{L} 269 \mathrm{~F}$ or wild-type $\epsilon$ subunits and wild type $\alpha, \beta$, and $\delta$ subunits.

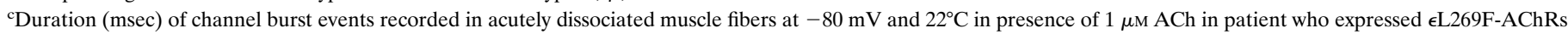
(Engel et al., 1996).

dhird component not detected.

${ }^{\text {e}}$ Single-channel conductance (in pA) as determined from the current-voltage relationship.

${ }^{\mathrm{f}}$ Number of compound muscle action potentials (CMAP) recorded over mouse gastrocnemius evoked by single nerve stimulus.

gThe percent decrease in amplitude of the 10th CMAP recorded over intrinsic muscles of the mouse hindpaw during repetitive-nerve stimulation at 5 Hz.

${ }^{\mathrm{h}}$ Miniature endplate current (MEPC) amplitude (nA) recorded in excised diaphragm.

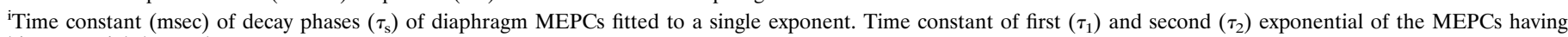
biexponential decay phase.

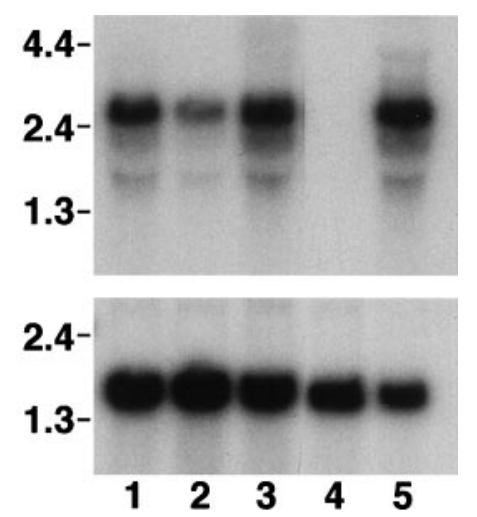

Figure 2. RNA blot analysis of $\epsilon \mathrm{L} 269 \mathrm{~F}$ transgene expression in muscle. Total RNA $(10 \mu \mathrm{g})$ from skeletal muscle of control mouse and individuals from $4 \epsilon$ L269F-transgenic lines was hybridized with the transgene probe $\epsilon \mathrm{NEO}$ (top panel, $24 \mathrm{hr}$ exposure) or the MCK probe (bottom panel, $4 \mathrm{hr}$ exposure). Lane 1, $\epsilon 5$; lane 2, $\epsilon$; lane 3, $\epsilon 12$; lane 4, control; lane 5, $\epsilon 14$. The ratios of steady state transgene mRNA levels are $1(\epsilon 9): 3(\epsilon 5, \epsilon 12)$ : $8(\epsilon 14)$. Although it is difficult to compare these levels with those of the endogenous $\epsilon$ mRNA [expressed only in the subsynaptic nuclei (Merlie and Sanes, 1985)], the abundance of the transgene mRNA seems much greater than the wild type.

$\sim 5$ months of age they seem to have less spontaneous exploratory activity than controls. They are also more susceptible than controls to fatal complications during pentobarbital anesthesia, probably attributable to respiratory muscle weakness. Formal strength testing of lines $\epsilon 5$ and $\epsilon 14$ revealed that these mice readily fatigued in comparison to their littermates. Figure 4 displays the results with two strength measures. In nearly all cases transgenic mice were able to grip either the wire or dowel at least briefly but tended to fatigue and drop off the apparatus well before $60 \mathrm{sec}$.
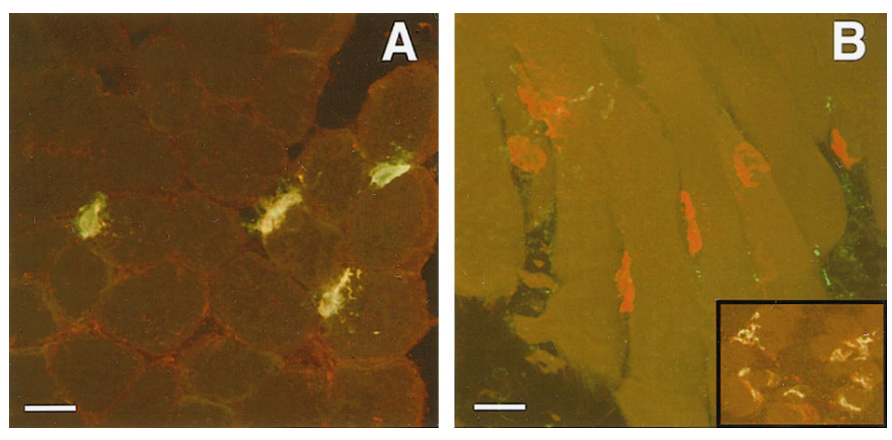

Figure 3. $\epsilon \mathrm{L} 269 \mathrm{~F}$-transgenic endplates express $\delta$ subunits, but not $\gamma$ subunits. $A$, The $\gamma$ - $\delta$-subunit-specific mAb 88B (Froehner et al., 1983), stained with Cy3-conjugated anti-mouse antibody, colocalizes with Cy2conjugated $\alpha$ bungarotoxin (double-stained endplates are yellow) on $\epsilon \mathrm{L} 269 \mathrm{~F}$-transgenic mouse endplates. Identical patterns were seen with mAbs specific for $\alpha, \beta$, and $\epsilon$ subunits. $B$, Section from the same muscle and $\epsilon$ L269F-transgenic mouse showing binding of Texas Red-conjugated $\alpha$ bungarotoxin $(T x-B T$, red $)$, but no binding of antibody to $\gamma$-subunit peptide (Gu and Hall, 1988), stained with Cy2-conjugated anti-rabbit antibody (double-stained endplates should be yellow) but staining with Texas Redconjugated $\alpha$ bungarotoxin $(T x-B T$, red $)$. As a positive control for the peptide-specific antiserum, the inset shows neonatal control muscle stained with anti- $\gamma$ antisera and Cy2-conjugated second antibody (green) along with Tx-BT (red, double-stained endplates are yellow). Calibration bar, $25 \mu \mathrm{M}$.

Control mice on average either remained hanging the full minute or climbed off. Transgenic mice were not able to climb off the apparatus.

\section{Electromyography}

In four of the lines of $\epsilon$ L269F-transgenic mice, single stimuli to peripheral nerves evoked repetitive CMAP in at least two of the 


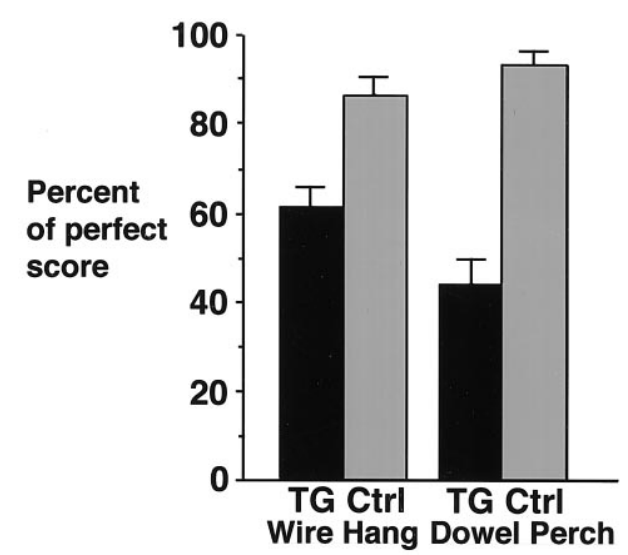

Figure 4. $\epsilon$ L269F-transgenic mice have skeletal muscle weakness. Transgenic mice (dark bars) performed significantly more poorly than control mice (light bars) on the wire-hang test $(61.5 \%$, compared with $86.7 \%$ for control) and on the dowel perch test (44.1\%, compared with $93.4 \%$ for control; $n=15 ; p<0.001)$. Perfect score $(100 \%)=1 \mathrm{~min}$ hang or escape.

three muscle groups tested (Table 1). The size and number of repetitive CMAP varied depending on the muscle groups tested, but were similar for the same muscle groups for different animals. The repetitive CMAP was always prominent in the gastrocnemius but was absent or diminished in the intrinsic hindpaw muscles. Figure $5 A$ shows a CMAP recorded from the gastrocnemius after a single stimulus to the sciatic nerve. Two additional action potentials follow the initial action potential. This repetitive firing of action potentials, which is similar to that seen in SCCMS, is caused by the prolongation of the endplate potential beyond the muscle fiber refractory period. Evoked CMAPs recorded in control mice were always single responses (Fig. $5 B$, Table 1).

The effect of repetitive nerve stimulation on the CMAP in the $\epsilon$ L269F-transgenic mice also depended on the muscle type. Responses evoked in gastrocnemius with repetitive stimulation at rates from 2 to $10 \mathrm{~Hz}$ were of constant amplitude to at least the 10th response in both transgenic and control. In comparison, stimulation at rates from 2 to $10 \mathrm{~Hz}$ while recording over the intrinsic muscles of the hindpaws of mice from three transgenic lines elicited decremental CMAP (Fig. 5C, D, Table 1). The mean decrement at $5 \mathrm{~Hz}$ stimulation for the hindpaw was $13.6 \pm 1.6 \%$ $(n=6)$ compared with a control decrement of $3.0 \pm 0.9 \%(n=$ $5 ; p<0.001)$. Decremental CMAPs of $25.6 \%$ during $5 \mathrm{~Hz}$ stimulation were also recorded over the forelimb flexor muscles of transgenic founder $\epsilon 4-0$ that did not breed. This decremental response, a pattern typical of myasthenic disorders, indicates the presence of a reduced safety factor of neuromuscular transmission in these muscles. Variable involvement of different muscle groups with prominent involvement of small muscles is also typical of SCCMS.

\section{Voltage-clamp analysis of endplate currents}

The altered muscle responses in $\epsilon$ L269F-transgenic mice indicated abnormalities in both kinetics and amplitudes of the MEPCs. We studied MEPCs using the classic two-electrode voltage clamp and hemidiaphragm preparation (Glaminovic, 1979) in lines $\epsilon 5$ and $\epsilon 14$. The kinetics of channel openings of junctional AChRs in the $\epsilon$ L269F-transgenic mice determine the time course of the spontaneous MEPCs, with the decay phase of MEPCs depending on the mean open duration of the AChR channels (Magleby and Stevens, 1972). MEPC decay phases in $\epsilon$ L269Ftransgenic mice were predominantly biphasic and had significantly
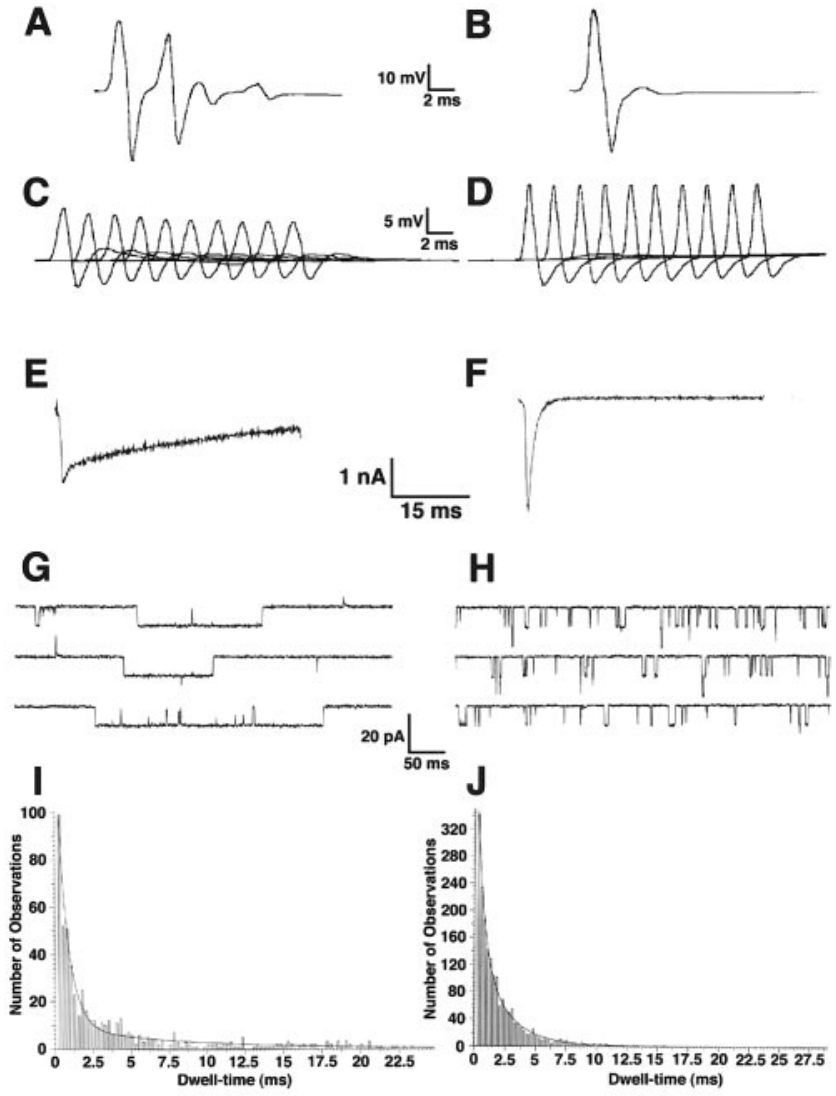

Figure 5. Abnormal neuromuscular transmission in $\epsilon$ L269F-transgenic mice. A, $\epsilon$ L269F-transgenic mouse. Repetitive compound muscle action potentials (CMAP) recorded over gastrocnemius, evoked by a single stimulus to sciatic nerve. The predominant repetitive CMAP occurs at an interval of $3.6 \mathrm{msec}$. $B$, Control mouse. CMAP recorded over gastrocnemius is a single action potential. $C, \epsilon \mathrm{L} 269 \mathrm{~F}$-transgenic mouse. Decremental CMAP recorded over intrinsic muscles of foot, evoked by stimulation of sciatic nerve at $10 \mathrm{hz}$. The amplitude of the CMAP decays by $18 \%$ by the 10th response. $D$, Control mouse. CMAP recorded over intrinsic muscles of foot, evoked by repetitive stimulation at $10 \mathrm{hz}$ have no decrement in amplitude. $E$, Miniature endplate current (MEPC) recorded from hemidiaphragm of $\epsilon \mathrm{L} 269 \mathrm{~F}$-transgenic mouse. The amplitude is $2 \mathrm{nA}$ and the decay time constant of the predominant decay component is 26.6 msec. $F$, MEPC recorded from control mouse, with an amplitude of $2.8 \mathrm{nA}$ and principal decay time constant of $1.4 \mathrm{msec}$. $G-J$, Single-channel currents $(G, H)$ and open time histograms $(I, J)$ recorded for endplate AChRs in dissociated flexor digitorum brevis (fdb) muscle fibers of $\epsilon \mathrm{L} 269 \mathrm{~F}$-transgenic mouse $(G, I)$ and control mouse $(H, J)$. Recordings were made at $-50 \mathrm{mV}$ holding potential. Calibration bars: $A, B, 10 \mathrm{mV}$, $2 \mathrm{msec}$; $D, 5 \mathrm{mV}, 1 \mathrm{msec}, E, F, 1 \mathrm{nA}, 15 \mathrm{msec} ;, H, 20 \mathrm{pA}, 50 \mathrm{msec}$.

prolonged decay phases (Fig. 5E, $F$, Table 1). The first component, which represented $\sim 60 \%$ of the decay in lines $\epsilon 5$ and $\epsilon 14$, had a mean time constant $\left(\tau_{1}\right)$ of $0.81 \pm 0.12 \mathrm{msec}(n=105)$, whereas the second component, representing $\sim 40 \%$ of the decay, had a much slower exponential course, with a mean time constant $\left(\tau_{2}\right)$ of $26.6 \pm 2.34 \mathrm{msec}(n=105)$. In contrast, a biexponential decay phase could be detected in only 4 of the 33 control fibers with a $\tau_{1}$ of $1.23 \pm 0.08 \mathrm{msec}$ and a $\tau_{2}$ of $3.47 \pm 3.18(n=4)$. Whereas the transgenic $\tau_{1}$ was slightly less than either the control $\tau_{1}$ or the time constant of the predominantly monophasic decays $\left(\tau_{\mathrm{s}}\right), 1.44 \pm 0.05 \mathrm{msec}(n=33)$, the transgenic $\tau_{2}$ was nearly eightfold longer than the control $\tau_{2}$. The presence of biphasic decay phases in MEPCs with one normal component and one slow component suggests either the presence of two populations of 
AChRs within the endplate or a single population with two predominant open states.

The decremental CMAP responses to repetitive stimulation in the hindpaw muscle of $\epsilon$ L269F-transgenic mice suggest a critical reduction in the safety factor of neuromuscular transmission. The amplitude of endplate currents is a principal determinant of the safety factor. We found that the quantally evoked MEPCs recorded from diaphragm muscle of the $\epsilon \mathrm{L} 269 \mathrm{~F}$-transgenic mice had reduced amplitude, $2.0 \pm 0.18 \mathrm{mV},(p<0.001 ; n=105,8$ animals) compared with $2.9 \pm 0.26,(n=33,4$ animals $)$ (Table 1$)$. This reduction of $31 \%$ in amplitude of the diaphragm MEPCs indicates a significant impairment in neuromuscular transmission, but probably would not be sufficient to lead to decremental CMAP responses in this muscle. In fact, a greater impairment of neuromuscular transmission in the diaphragm might cause lethal respiratory insufficiency. The foot muscles or forelimb flexors, where the decremental CMAP responses were recorded, were not studied by voltage-clamp analysis.

\section{Patch-clamp}

Patch-clamp analysis of ACh-induced single channels in $\epsilon$ L269Ftransgenic endplates revealed channels with prolonged open durations. At a $50 \mathrm{mV}$ holding potential, in the presence of $400 \mathrm{~nm}$ ACh, muscle fibers from transgenic and control mice exhibited channel events of both short and long duration (Fig. 5, G-J, Table 1). The short duration events were similar in duration for the transgenic $\left(\tau_{1}=0.52 \pm 0.08 \mathrm{msec}\right)$ vs control $\left(\tau_{1}=0.31 \pm 0.09\right)$. The long duration events of the $\epsilon$ L269F-transgenic mice $\left(\tau_{2}=\right.$ $13.2 \pm 2.55, n=6$ ) were more than threefold longer than the corresponding events recorded from control mice $\left(\tau_{2}=3.85 \pm\right.$ $0.35 ; n=4, p<0.02$ ). These two kinetic states, which probably represent events evoked by single-and double-ligand occupancy of the AChRs, were similar to the findings of patch-clamp analysis of an SCCMS patient that bears the $\epsilon$ L269F mutation (Table 1) (Engel et al., 1996), and can account for the prolonged decay phases of the transgenic MEPCs. There was no difference in single-channel conductance between transgenic $(76.5 \pm 13.1 \mathrm{pS})$ and control endplate AChRs (75.1 $\pm 16 \mathrm{pS})$.

\section{Light microscopy}

In transverse sections through endplate regions, transgenic muscle fibers demonstrated increased eosinophilic staining over either the entire muscle fiber or in the portion closest to the endplate region, suggesting a localized hypercontracture (Fig. 6A). This was supported by teased fiber studies showing localized contractures at the endplate (data not shown). These changes tended to be the principal light microscopic changes in younger animals (2-4 months). In older transgenic animals ( $>4$ months) within the endplate region, there were scattered angulated or atrophic fibers and some degenerating fibers. Fibers undergoing splitting and fibers with increased central nuclei were common (Fig. 6C). There was intense staining for acid phosphatase at most motor endplates and patchy acid phosphatase activity throughout many fibers in the endplate region (Fig. 6D), indicating increased lysosomal activity, as commonly seen in myopathies. A similar picture was present in all muscle groups tested.

Histochemical methods that detect deposits of ionized $\mathrm{Ca}^{2+}$ stained many endplate regions intensely in each of the four $\epsilon$ L269F-transgenic lines (Fig. 6B). The $\mathrm{Ca}^{2+}$ stain is deposited focally along the perimeter of the muscle fiber, over regions that colocalize with acetylcholinesterase, indicating the presence of a neuromuscular synapse (Fig. 6A). Similar intense staining near the endplate region using the GBHA method has been reported for the SCCMS patient bearing the $\epsilon$ L269F mutation (Engel et al., 1982; Gomez and Gammack, 1995). In contrast to the myopathic features, which seemed to increase with age, the frequency of endplates with GBHA staining decreased with age.

\section{Electron microscopy}

Forelimb neuromuscular junctions of mice from two of the transgenic lines were examined by electron microscopy (Fig. 7). Nearly every junction examined showed subsarcolemmal vacuoles of a range of sizes (Fig. $7 A, B$ ) having the appearance of dilated sarcoplasmic reticulum. Most of these appeared empty, but some contained electron-dense granular material and/or membranous debris. The vacuoles were confined entirely to the junctional regions of the muscle fibers. Most junctions also contained lysosomes filled with membranous debris and degenerating subsarcolemmal organelles. Postsynaptic membrane folds appeared simplified with shallow secondary synaptic clefts but showed no signs of degeneration. The primary synaptic clefts were not significantly widened. Junctional basal laminae were neither duplicated nor thickened (Fig. 7A,B).

Many of the mitochondria in the subjunctional sarcoplasm were markedly enlarged, $>10$ times the size of the mitochondria in the adjacent nerve terminus (Fig. $7 B$ ). The cristae in these giant mitochondria stained heavily with osmium and contained minute osmiophilic granules. Some mitochondria were frankly degenerating (Fig. 7A, $B$ ). Degenerating nuclei with crenated membranes, condensed chromatin, cytoplasmic inclusions, and myelinoid membranous debris were occasionally seen (Fig. 7C). Except for the absence of an acutely degenerating postsynaptic membrane, these ultrastructural abnormalities in 4-month-old $\epsilon$ L269Ftransgenic mice are identical to the endplate myopathy described in the SCCMS (Engel et al., 1982).

\section{DISCUSSION}

The slow-channel syndrome is a prototype for a disorder of hereditary excitotoxicity. The AChR $\epsilon$ subunit point mutation $\epsilon \mathrm{L} 269 \mathrm{~F}$ is one of several mutations that have been identified in the SCCMS (Gomez and Gammack, 1995; Engel et al., 1996). In the present study we demonstrate that the $\epsilon \mathrm{L} 269 \mathrm{~F}$ mutation greatly prolongs the single opening events using the oocyte expression system. The predominant opening events have durations of either 19.95 or $45.44 \mathrm{msec}$, compared with the control events of 3.63 msec. A similar study has shown that the AChRs with the $\epsilon$ L269F mutation, expressed in human embryonic kidney (HEK), fibroblasts contain three open time components (Engel et al., 1996) that differ from the values that we obtained in Xenopus oocytes. In the HEK cells a $50.6 \mathrm{msec}$ time constant seems to be similar to the $45 \mathrm{msec}$ component in the oocyte. The $20 \mathrm{msec}$ component seen in oocytes, however, was not present in the HEK cells, in which faster openings $(0.04$ and $0.28 \mathrm{msec})$ were the most common. The absence of these fast components in the oocytes may be attributable to technical reasons, such as lower recording temperature, but this result is in accord with a recent finding that $\mathrm{AChR}$ channel kinetics can be influenced by the expression system (Zanello et al., 1996). Interestingly, the endplate AChRs in acutely dissociated muscle fibers of one $\epsilon \mathrm{L} 269 \mathrm{~F}$ patient had single-channel open times of $7.21 \mathrm{msec}$ and bursts of up to 16.67 msec (at $-80 \mathrm{mV}$ ) (Engel et al., 1996) in close agreement with our findings.

Whereas the above in vitro findings correlate the identified mutation with the electrophysiological findings in the SCCMS, 

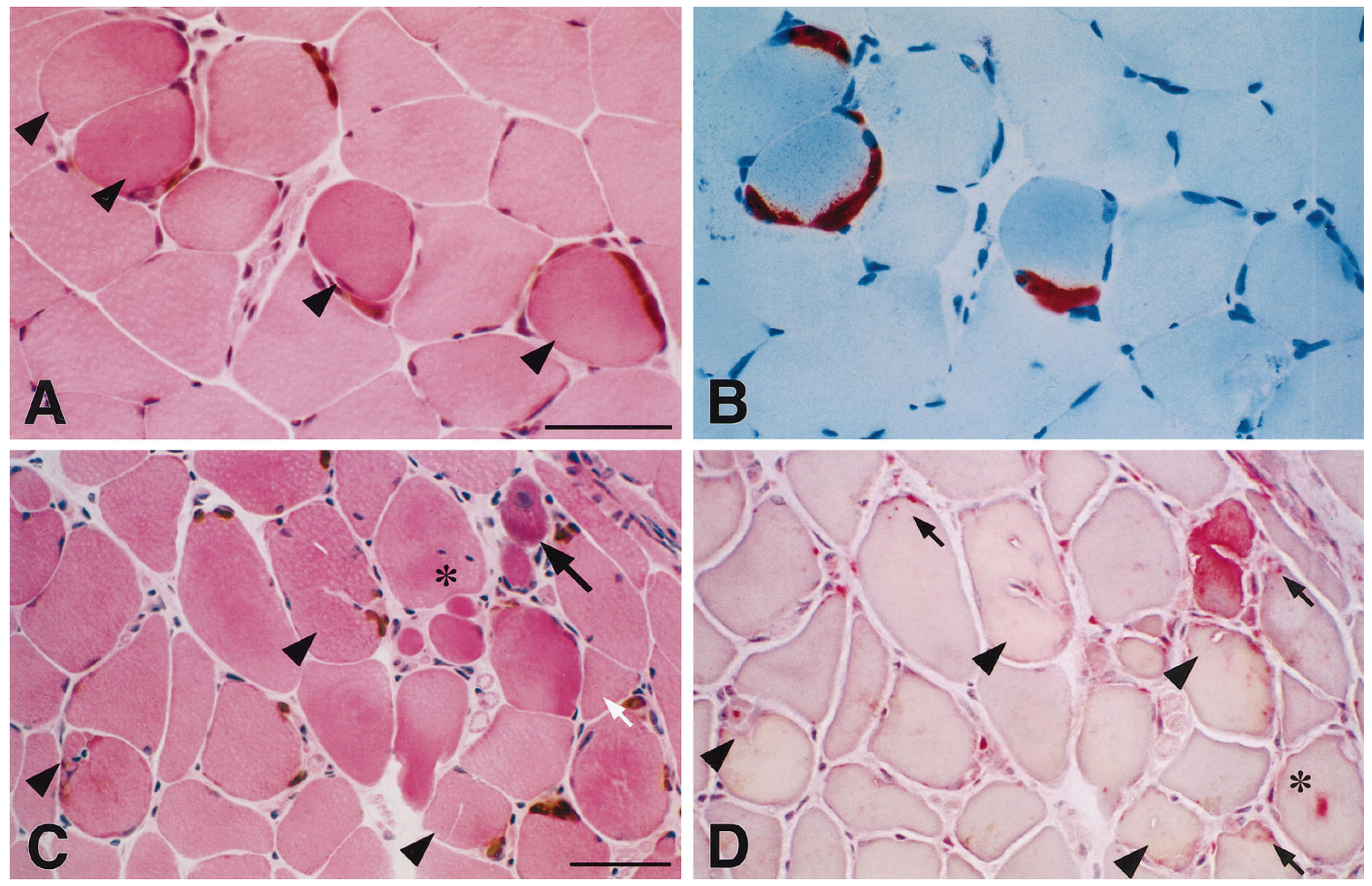

Figure 6. $\quad \epsilon$ L269F-mice have segmental myopathy and $\mathrm{Ca}^{2+}$-overloaded endplates. Serial transverse sections of forelimb flexors of 4-month-old mouse $(A, B)$ and of triceps muscle of 10-month-old mouse $(C, D)$ were stained for cholinesterase (brown stain, hematoxylin and eosin counterstain) to localize motor endplates $(A, C)$, glyoxal bis (2-hydroxyanil) (GBHA, red stain, methylene blue counterstain) to localize accumulation of ionized calcium (B), and for acid phosphatase (red stain, hematoxlin counterstain) to localize lysosomal activity $(D)$. In $A$, four of the muscle fibers have increased eosinophilic staining at or near endplate regions (arrowheads), suggesting either early degeneration or localized contracture. In $B$, the adjacent section, three of these fibers stain intensely for GBHA (red) in a focal distribution on the periphery of the fiber, suggesting accumulation of $\mathrm{Ca}^{2+}$ in the subsynaptic regions. In older muscle $(C)$ myopathic features are prevalent in the endplate regions. The splitting fibers (arrowheads), degenerating fibers (black arrow), atrophic fibers (white arrow), and central nuclei (asterisk) seen here are typical of multiple fields and demonstrate the combined neurogenic and myopathic changes that are the classical features of the slow-channel congenital myasthenic syndrome. The fiber splitting occurs at the endplate regions. In $D$, the adjacent section, the necrotic fiber in $C$ stains intensely for acid phosphatase. Both normal-appearing fibers (arrows) and splitting fibers (arrowheads) have focal acid phosphatase staining near the endplate regions. At the endplate region of one fiber (asterisk) there is intense staining for acid phosphatase centrally. Calibration bar, $50 \mu \mathrm{M}$.

they do not provide a basis for the progressive myopathy and synaptic degeneration seen in this syndrome. Targeted expression in transgenic mouse muscle of $\epsilon \mathrm{L} 269 \mathrm{~F}$ mRNA induced focal $\mathrm{Ca}^{2+}$ deposition and accumulation of vacuoles, lysosomes, and degenerating organelles in the postsynaptic region of the neuromuscular junction. The mice develop electrical evidence of impaired neuromuscular transmission and clinically evident fatigability of the forelimb muscles as in the SCCMS. The kinetics of the MEPCs and single channels recorded from $\epsilon$ L269F-transgenic muscle fibers indicate that the properties of the AChR channels expressed in these mice resemble those of the $\epsilon$ L269F-AChRs expressed in oocytes. These observations strongly suggest a role for the $\epsilon \mathrm{L} 269 \mathrm{~F}$ mutation in the pathogenesis of the spectrum of abnormalities in this disorder.

The situation in the $\epsilon$ L269F-transgenic mice differs from that of the human disease, which is autosomal dominant, in that the mutation is overexpressed, not co-expressed to the same level with the wild-type $\epsilon$ subunit. This may have several implications. First, because of overexpression of the transgene, the predominant $\epsilon$ subunit species is probably $\epsilon \mathrm{L} 269 \mathrm{~F}$, and the transgenic mice may approach a phenotype equivalent to the human homozygous mutant state. This would explain the more severe disease. Second, because of overexpression of the transgene it is conceivable that the $\epsilon$ L269F subunit might displace one of the other wild-type subunits, such as the $\delta$ subunit, and thereby alter the normal AChR subunit stoichiometry. This is unlikely, because the $\epsilon$ L269F-transgenic endplates stain intensely with the $\gamma-\delta$ specific monoclonal antibody, 88B (Froehner et al., 1983) (Fig. 3), whereas they do not stain with a peptide-specific anti- $\gamma$ polyclonal antibody ( $\mathrm{Gu}$ and Hall, 1988) nor is the $\gamma$ mRNA detected by northern blot (data not shown). This indicates that there is abundant $\delta$-subunit protein in the transgenic endplates. Also, the channel properties of $\delta$-less channels have been studied and have much lower conductances and shorter open times than the channels measured in the transgenic muscle fibers (Kullberg et al., 1990). Finally, we cannot rule out a role of other transgene actions that would not be present in the SCCMS, such as a dominant negative effect of overexpressed $\epsilon$ subunit, that alters AChR 

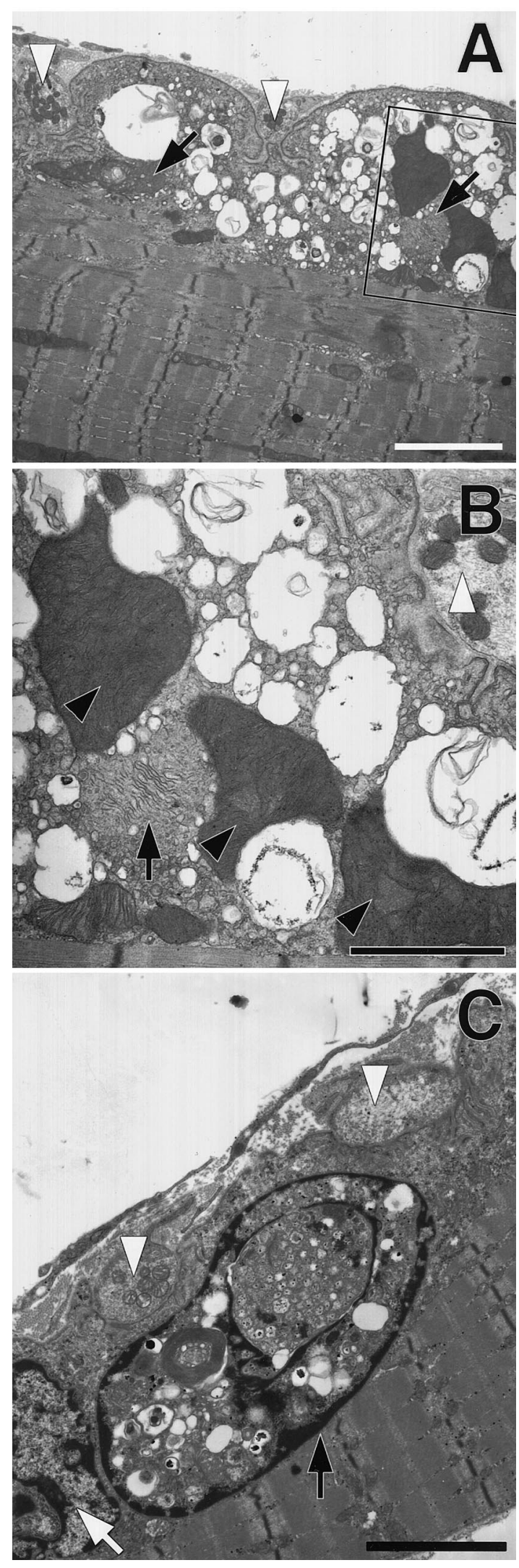

Figure 7. $\epsilon \mathrm{L} 269 \mathrm{~F}$-mice have degeneration of the neuromuscular synapse. Neuromuscular junctions from forelimb flexor muscles of 4-month-old $\epsilon$ L269F-transgenic mice. To facilitate orientation all nerve termini are indicated using white arrowheads. In all three views the postsynaptic folds are simplified, whereas the adjacent the nerve termini (white arrowheads) assembly or the effect of possible splicing artifacts seen in the RNA blot. Nevertheless, the similarity of the electrophysiological and pathological changes seen in these mice, from whole animal to the single channel to the changes seen in oocytes and in patients argues that the principal properties of the mutant are reproduced in these mice.

\section{Altered electrophysiology}

Each of the electrophysiological abnormalities in the $\epsilon$ L269Ftransgenic mice can now be ascribed to the effects of a single point mutation. Prolonged MEPC decay phases are caused by the long duration activation events of the slow $\epsilon$ L269F-AChR channels in oocytes and muscle fibers. The repetitive CMAP that follow single nerve stimuli result directly from the prolonged endplate currents, because the resultant prolonged endplate potentials outlast the preceding muscle fiber refractory period. The decremental CMAP responses arise from the diminished MEPC amplitudes, which cause a reduced neuromuscular safety factor of neuromuscular transmission. The reduced MEPCs are unrelated to the single-channel conductance of the $\epsilon \mathrm{L} 269 \mathrm{~F}-\mathrm{AChRs}$, because this is normal, but may have several explanations: (1) the density of AChRs may be reduced; (2) the endplate architecture may be altered by the destructive changes occurring in the junctional sarcoplasm; (3) the sodium driving force for the MEPCs may be reduced by an increase in the local sodium concentration of the junctional sarcoplasm, because of the cation overload; and (4) the endplate AChRs may exhibit a greater tendency to desensitize, which could reduce the responsiveness of the postsynaptic membrane.

\section{Calcium-induced transsynaptic degeneration}

Intracellular $\mathrm{Ca}^{2+}$ accumulation through glutamate and nicotinic receptors plays a critical role in several experimental models of excitotoxicity (Kawabuchi, 1982; Salpeter et al., 1982; Choi, 1985). The normal AChR channel is highly permeable to $\mathrm{Ca}^{2+}$ (Decker and Dani, 1990). Preliminary data suggest that $\epsilon$ L269F-AChRs have no difference in $\mathrm{Ca}^{2+}$ permeability (Gomez et al., unpublished observations). Although the GBHA histochemical stain shows focal $\mathrm{Ca}^{2+}$ accumulation at the motor endplate, it does not permit subcellular localization of the excess $\mathrm{Ca}^{2+}$ (Evans, 1974; Kawabuchi, 1982). Other approaches have demonstrated an increase in $\mathrm{Ca}^{2+}$ in cytoplasmic, mitochondrial, or endoplasmic reticulum in neurons after excitation (Andrews et al., 1988; Werth and Thayer, 1994; White and Reynolds, 1995). In the $\epsilon \mathrm{L} 269 \mathrm{~F}$ mice, the ultrastructural findings at the motor endplate suggest that sarcoplasmic reticulum and mitochondria participate in $\mathrm{Ca}^{2+}$ buffering. The myriads of vacuoles in the junctional sarcoplasm, which are also seen in the SCCMS (Engel et al., 1982; Gomez et al., 1996b), seem to arise in part from the sarcoplasmic reticulum. Many are filled with electron-dense granules suggestive of $\mathrm{Ca}^{2+}$ precipitates.

\section{$\leftarrow$}

seem normal. $A$, large vacuoles containing membranous or granular debris fill the junctional sarcoplasm. The composition of the vacuoles can be seen more clearly in the enlargement from the boxed section $(B)$. The mitochondria in the muscle fiber in $A$ and in $B$ (inset) are greatly enlarged compared with those in the nerve termini. Black arrows indicate what seem to be two degenerating mitochondria. Three mitochondria are massively enlarged and have densely packed cristae (black arrowheads). $C$, A degenerating myonucleus (black arrow) filled with autophagic debris and cytoplasmic contents lies immediately beneath a neuromuscular junction and adjacent to a relatively normal-appearing nucleus (white arrow). Calibration bars: $A, 20 \mathrm{nM} ; B, 10 \mathrm{nM} ; C, 15 \mathrm{~nm}$. 
The junctional subsarcolemmal mitochondria in the $\epsilon \mathrm{L} 269 \mathrm{~F}$ transgenic mice demonstrate two types of abnormalities, suggesting a progression of changes. Many are massively enlarged compared with the presynaptic nerve terminal mitochondria and intermyofibrillar mitochondria. Abnormally enlarged and proliferating mitochondria are associated with inherited defects in mitochondrial oxidative metabolism and in aging tissue (Wilson and Franks, 1975). Because mitochondria use oxidative metabolism to buffer large $\mathrm{Ca}^{2+}$ loads, the hypertrophic changes in these mice may reflect the response of the organelle to the increased energy demands. A smaller number of mitochondria appear dilated or degenerating, as has been seen in SCCMS (Engel et al., 1982).

In addition to enlarged and degenerating mitochondria, the junctional sarcoplasm of $\epsilon \mathrm{L} 269 \mathrm{~F}$-transgenic mice contains degenerating nuclei, which along with the other organellar changes, occurs in the absence of frank degeneration of postsynaptic folds. Degenerating nuclei and mitochondria are seen in nearly all reported cases of SCCMS, whereas the type and degree of changes in the synaptic cleft and postsynaptic membrane are quite variable (Engel et al., 1982; Oosterhuis et al., 1987; Gomez et al., 1996b). Together with the findings in the transgenic mice, this suggests that, in this complicated ultrastructural picture, focal organellar degeneration at the neuromuscular junction is the earliest change, and that the abnormalities at the basement membrane and postsynaptic membrane represent a more chronic process.

The organellar degeneration associated with prolonged synaptic currents is most likely a consequence of transsynaptic $\mathrm{Ca}^{2+}$. overload. It will be critical to identify the pathways responsible for this process because they may be similar to those involved in stroke, epilepsy, and certain neurodegenerative diseases (Choi, 1992). Possibilities include the following: (1) intracellular damage from calcium-activated enzymes, such as calpain, DNase, or phospholipase (Salpeter et al., 1982; Choi, 1992); (2) depletion of energy stores in the muscle fiber because of the metabolic demands caused by the cation overload; (3) free radical-mediated damage of subcellular components. Excessive production of free radicals could arise from at least two sources. First, the neuronal form of nitric oxide synthase, which is stimulated by $\mathrm{Ca}^{2+}$, forms a tight noncovalent linkage with the $\alpha$ syntrophin moiety of the dystrophin complex in the neuromuscular junction (Brenman et al., 1995). Excessive $\mathrm{Ca}^{2+}$ entry might give rise to overproduction of nitric oxide that could lead to oxidative damage (Dawson et al., 1991). Second, under normal resting conditions mitochondria are the greatest cellular source of reactive oxygen species (ROS) (Beal, 1995). Their production of ROS increases with metabolic load (Dykens, 1994). The increase in mitochondrial size and buffering activity in the muscle fiber would lead to a further increases in ROS production.

This animal model of a human disorder of synaptic transmission demonstrates the connection between a mutation resulting in a kinetic disturbance in ion channel function and a progressive degenerative disease. Furthermore, it suggests a pathological sequence of events and establishes a means of investigating the pathways leading to excitotoxic synaptic degeneration that are likely to have counterparts within other forms of excitotoxicity.

\section{REFERENCES}

Andrews SB, Leapman RD, Landis DM, Reese TS (1988) Activitydependent accumulation of calcium in Purkinje cell dendritic spines. Proc Natl Acad Sci USA 85:1682-1685.

Barka T (1960) A simple azo-dye method for histochemical demonstration of acid phosphatase. Nature 187:248-249.
Beal MF (1995) Aging, energy, and oxidative stress in neurodegenerative diseases. Ann Neurol 38:357-366.

Boulter J, Luyten W, Evans K, Mason P, Ballivet M, Goldman D, Stengelin S, Martin G, Heinemann S, Patrick J (1985) Isolation of a clone coding for the alpha-subunit of a mouse acetylcholine receptor. J Neurosci 5:2545-2452.

Brehm P, Kullberg R (1987) Acetylcholine receptor channels on adult mouse skeletal muscle are functionally identical in synaptic and nonsynaptic membrane. Proc Natl Acad Sci USA 84:2550-2554.

Brenman JE, Chao DS, Xia HH, Aldape K, Bredt DS (1995) Nitric oxide synthase complexed with dystrophin and absent from skeletal muscle sarcolemma in Duchenne muscular dystrophy. Cell 82:743-752.

Buskin JN, Jaynes JB, Chamberlain JS, Hauschka SD (1985) The mouse muscle creatine kinase cDNA and deduced amino acid sequences: comparison to evolutionarily related enzymes. J Mol Evol 22:334-341.

Bygrave FL, Roberts HR (1995) Regulation of cellular calcium through signaling cross-talk involves an intricate interplay between the actions of receptors, G-proteins, and second messengers. FASEB J 9:1297-1303.

Choi DW (1985) Glutamate neurotoxicity in cortical cell culture is calcium dependent. Neurosci Lett 58:293-297.

Choi DW (1992) Excitotoxic cell death. J Neurobiol 23:1261-1276.

Chomczynski P, Sacchi N (1987) Single-step method of RNA isolation by acid guanidinium thiocyanate-phenol-chloroform extraction. Anal Biochem 162:156-159.

Dawson VL, Dawson TM, London ED, Bredt DS, Snyder SH (1991) Nitric oxide mediates glutamate neurotoxicity in primary cortical cultures. Proc Natl Acad Sci USA 88:6368-6371.

Decker ER, Dani JA (1990) Calcium permeability of the nicotinic acetylcholine receptor: the single-channel calcium influx is significant. J Neurosci 10:3413-3420.

Dykens JA (1994) Isolated cerebral and cerebellar mitochondria produce free radicals when exposed to elevated $\mathrm{Ca}^{2+}$ and $\mathrm{Na}^{+}$: implications for neurodegeneration. J Neurochem 63:584-591.

Engel AG, Lambert EH, Mulder DM, Torres CF, Sahashi K, Bertorini TE, Whitaker JN (1982) A newly recognized congenital myasthenic syndrome attributed to a prolonged open time of the acetylcholineinduced ion channel. Ann Neurol 11:553-569.

Engel AG, Ohno K, Milone M, Wang HL, Nakano S, Bouzat C, Pruitt JN, Hutchinson DO, Brengman JM, Bren N (1996) New mutations in acetylcholine receptor subunit genes reveal heterogeneity in the slowchannel congenital myasthenic syndrome. Hum Mol Genet 5:1217-1227.

Evans RH (1974) The entry of labeled calcium into the innervated region of the mouse diaphragm. J Physiol (Lond) 240:517-533.

Feinberg AP, Vogelstein B (1984) A technique for radiolabeling DNA restriction endonuclease fragments to high specific activity. Addendum. Anal Biochem 137:266-267.

Froehner SC, Douville K, Klink S, Culp WJ (1983) Monoclonal antibodies to cytoplasmic domains of the acetylcholine receptor. J Biol Chem 258:7112-7120.

Gardner PD (1990) Nucleotide sequence of the epsilon-subunit of the mouse muscle nicotinic acetylcholine receptor. Nucleic Acids Res 18:6714.

Ghosh A, Greenberg ME (1995) Calcium signaling in neurons: molecular mechanisms and cellular consequences. Science 268:239-247.

Glaminovic MI (1979) Voltage clamping of unparalysed cut diaphragm for the study of transmitter release. J Physiol (Lond) 290:467-480.

Gomez CM, Richman DP (1985) Monoclonal anti-acetylcholine receptor antibodies with differing capacities to induce experimental autoimmune myasthenia gravis. J Immunol 135:234-241.

Gomez CM, Gammack JT (1995) A leucine-to-phenylalanine substitution in the acetylcholine receptor ion channel in a family with the slow-channel syndrome. Neurology 45:982-985.

Gomez CM, Bhattacharyya BB, Charnet P, Day JW, Labarca C, Wollmann RW, Lambert EH (1996a) A transgenic mouse model of the slow-channel syndrome. Muscle Nerve 19:79-87.

Gomez CM, Ricardo Maselli BS, Lasalde J, Tamamizu S, Cornblath DR, Lehar M, McNamee M, Kuncl RW, Pestronk A (1996b) A $\beta$ subunit mutation in the acetylcholine receptor channel gate causes severe slowchannel syndrome. Ann Neurol 39:717-723.

Gorman CM, Moffat LF, Howard BH (1982) Recombinant genomes which express chloramphenicol acetyltransferase in mammalian cells. Mol Cell Biol 2:1044-1051.

Gu Y, Hall ZW (1988) Immunological evidence for a change in subunits 
of the acetylcholine receptor in developing and denervated rat muscle. Neuron 1:117-125.

Hogan R, Costantini F, Lacey E (1986) Manipulating the mouse embryo: a laboratory manual. Cold Spring Harbor, NY: Cold Spring Harbor Laboratory.

Johnson JE, Wold BJ, Hauschka SD (1989) Muscle creatine kinase sequence elements regulating skeletal and cardiac muscle expression in transgenic mice. Mol Cell Biol 9:3393-3399.

Kashiwa HK (1970) Calcium phosphate in osteogenic cells. A critique of the glyoxal bis(2-hydroxyanil) and the dilute silver acetate methods. Clin Orthop Rel Res 70:200-211.

Kawabuchi M (1982) Neostigmine myopathy is a calcium ion-mediated myopathy initially affecting the motor end-plate. J Neuropathol Exp Neurol 41:298-314.

Kullberg R, Owens JL, Camacho P, Mandel G, Brehm P (1990) Multiple conductance classes of mouse nicotinic acetylcholine receptors expressed in Xenopus oocytes. Proc Natl Acad Sci USA 87:2067-2071.

Lapolla RJ, Mayne KM, Davidson N (1984) Mouse muscle nicotinic acetylcholine receptor $\delta$ subunit: cDNA sequence and gene expression. Proc Natl Acad Sci USA 81:7970-7974.

Magleby KL, Stevens CF (1972) A quantitative description of end-plate currents. J Physiol (Lond) 233:173-197.

Maselli R, Mass D, Distad B, Richman D (1991) Anconeus muscle: a human preparation suitable for in vitro microelectrode studies. Muscle Nerve 14:1189-1192.

Maselli R, Nelson D, Richman D (1989) Effects of a monoclonal antiacetylcholine receptor antibody on the avian end-plate. J Physiol (Lond) 411:271-283.

Merlie JP, Sanes JR (1985) Concentration of acetylcholine receptor mRNA in synaptic regions of adult muscle fibres. Nature 317:66-68.

Mishina M, Takai T, Imoto K, Noda M, Takahashi T, Numa S, Methfessel C, Sakmann B (1986) Molecular distinction between fetal and adult forms of muscle acetylcholine receptor. Nature 321:406-411.

Namba T, Nakamura T, Grob D (1967) Staining for nerve fiber and cholinesterase activity in fresh frozen sections. Am J Clin Pathol 7:74-77.

Nelson S, Shelton GD, Lei S, Lindstrom JM, Conti TB (1992) Epitope mapping of monoclona antibodies to Torpedo acetylcholine receptor gamma subunits, which specifically recognize the epsilon subunit of mammalian muscle acetylcholine receptor. J Neuroimmunol 36:13-27.

Ohno K, Hutchinson D, Milone M, Brengman J, Bouzat C, Sine S, Engel A (1995) Congenital myasthenic syndrome caused by prolonged acetylcholine receptor channel openings due to a mutation in the M2 domain of the $\epsilon$ subunit. Proc Natl Acad Sci USA 92:758-762.

Oosterhuis HJ, Newsom-Davis J, Wokke JH, Molenaar PC, Weerden TV, Oen BS, Jennekens FG, Veldman H, Vincent A, Wray DW (1987) The slow channel syndrome: two new cases. Brain 110:1061-1079.
Ophoff RA, Terwindt GM, Vergouwe MN, Vaneijk R, Oefner PJ, Hoffman S, Lamerdin JE, Mohrenweiser HW, Bulman DE, Ferrari M (1996) Familial hemiplegic migraine and episodic ataxia type-2 are caused by mutations in the $\mathrm{Ca}^{2+}$ channel gene cacnl1a4. Cell 87:543-552.

Rungby J, Kassem M, Eriksen EF, Danscher G (1993) The von Kossa reaction for calcium deposits: silver lactate staining increases sensitivity and reduces background. Histochem J 25:446-451.

Saiki RK, Gelfand DH, Stoffel S, Scharf SJ, Higuchi R, Horn GT, Mullis KB, Erlich HA (1988) Primer-directed enzymatic amplification of DNA with a thermostable DNA polymerase. Science 239:487-491.

Salpeter MM, Leonard JP, Kasprzak H (1982) Agonist-induced postsynaptic myopathy. Neurosci Comment 1:73-83.

Sambrook J, Fritsch FE, Maniatis T (1989) Molecular cloning: a laboratory manual, 2nd Ed. Cold Spring Harbor, NY: Cold Spring Harbor.

Shiang R, Ryan SG, Zhu YZ, Hahn AF, O'Connell P, Wasmuth JJ (1993) Mutations in the alpha 1 subunit of the inhibitory glycine receptor cause the dominant neurologic disorder, hyperekplexia. Nat Genet 5:351-358.

Sine SM, Ohno K, Bouzat C, Auerbach A, Milone M, Pruitt JN, Engel AG (1995) Mutation of the acetylcholine receptor a subunit causes a slowchannel myasthenic syndrome by enhancing agonist binding affinity. Neuron 15:229-239.

Steinlein OK, Mulley JC, Propping P, Wallace RH, Phillips HA, Sutherland GR, Scheffer IE, Berkovic SF (1995) A missense mutation in the neuronal nicotinic acetylcholine receptor alpha 4 subunit is associated with autosomal dominant nocturnal frontal lobe epilepsy. Nat Genet 11:201-203.

Treinin M, Chalfie M (1995) A mutated acetylcholine receptor subunit causes neuronal degeneration in C. elegans. Neuron 14:1-20.

Tzartos SJ, Lindstrom JM (1980) Monoclonal antibodies used to probe acetylcholine receptor structure: localization of the main immunogenic region and detection of similarities between subunits. Proc Natl Acad Sci USA 77:755-759.

Werth JL, Thayer SA (1994) Mitochondria buffer physiological calcium loads in cultured rat dorsal root ganglion neurons. J Neurosci 14:348-356.

White RJ, Reynolds IJ (1995) Mitochondria and $\mathrm{Na}^{+} / \mathrm{Ca}^{2+}$ exchange buffer glutamate-induced calcium loads in cultured cortical neurons. J Neurosci 15:1318-1328.

Wilson P, Franks L (1975) The effect of age on mitochondrial ultrastructure and enzymes. Adv Exp Med Biol 53:171-183.

Zanello LP, Aztiria E, Antonelli S, Barrantes FJ (1996) Nicotinic acetylcholine receptors channels are influenced by the physical state of their membrane environment. Biophys J 70:2155-2164. 